while their oral glucose tolerance improved. Xanthurenic acid may act as an insulin antagonist during pregnancy and sometimes cause gestational diabetes. Adaptation of insulin production and release to increasing synthesis of an insulin antagonist during pregnancy may determine whether or not a disturbance in the glucose tolerance will result. Nevertheless, it remains to be proved whether there is a relation between xanthurenic acid and gestational diabetes. Oral administration of vitamin $\mathbf{B}_{6}$ certainly improves significantly the oral glucose tolerance in gestational diabetes, but it is most important to know whether vitamin $\mathbf{B}_{6}$ given prophylactically could have a long-term influence by preventing the development of gestational diabetes during pregnancy.

\section{References}

${ }^{1}$ Beischer, N. A., and Lowry, J., fournal of Obstetrics and Gynaecology of the British Commonwealth, 1965, 70, 685 .

2 Dandrow, R. V., and O'Sullivan, J. B., American fournal of Obstetrics and Gynecology, 1966, 96, 1144 .

${ }^{3}$ Baird, J., fournal of Endocrinology, 1969, 44, 139.
${ }^{4}$ Campbell, N., Dyke, D. A., and Taylor, K. W., Fournal of Obstetrics and Gynaecology of the British Commonwealth, 1971, 78, 498.

5 Sprince, H., et al., American fournal of Obstetrics and Gynecology, 1951, 62,84 .

${ }^{6}$ Zartman, E. R., Barnes, A. C., and Hicks, D. J., American Fournal of Obstetrics and Gynecology, 1955, 70, 645.

${ }^{7}$ Brown, R. R., Thornton, M. J., and Price, J. M., fournal of Clinical Investigation, 1961, 40, 617 .

${ }^{8}$ Murakami, E., Fournal of Biochemistry, 1968, 63, 573.

${ }^{9}$ Luhby, A. L., et al., American fournal of Clinical Nutrition, 1971, 24, 684.

1 World Health Organization, Report of Expert Committee on Diabetes Mellitus. Technical report Series, No. 310. Geneva, W.H.O., 1965.

11 Schwarz, R. H., and Fields, G. A., Obstetrical and Gynecological Survey, 1971, 26, 277 .

12 Atkin, L., et al., Industrial and Engineering Chemistry (Analytical Edition), 1943, 15, 141 .

13 Wachstein, M., and Gudaitis, A., American Fournal of Clinical Pathology, $1952,22,652$.

14 Kyle, G. C., in Textbook of Gynecologic Endocrinology, ed. J. J. Gold, p. 621 . New York, Harper and Row, 1968.

15 Carrington, E. R., and McWilliams, N. B., American fournal of Obstetrics and Gynecology, 1966, 96, 922.

16 Pedersen, J., The Pregnant Diabetic and her Newborn. Problems and Pedersen, J., The Pregnant Diabetic and her Ner

17 Kotake, Y., and Inada, T. J., Biochemistry, 1953, 40, 291.

18 Kotake, Y., and Murakami, E., American fournal of Clinical Nutrition, $1971,24,826$.

${ }^{19}$ Hytten, F. E., and Lind, T., Diagnostic Indices in Pregnancy, p. 52. Basel, CIBA-Geigy, 1973.

\title{
Defective Innervation of Heart in Diabetic Autonomic Neuropathy
}

\author{
R. H. LLOYD-MOSTYN, P. J. WATKINS
}

British Medical fournal, 1975, 3, 15-17

\begin{abstract}
Summary
Heart rate responses to autonomic stimulation and inhibition were studied in 13 diabetics with autonomic neuropathy. Parasympathetic function was impaired in all patients and sympathetic function in most. One patient's heart appeared to be totally denervated. The consequences of cardiac denervation include tachycardia, a fixed heart rate, and a possible tendency to cardiac dysrhythmias, which caused spontaneous cardiac arrests in three patients.
\end{abstract}

\section{Introduction}

Diabetic autonomic neuropathy may have widespread consequences, and many abnormalities of the peripheral vascular system have been described. ${ }^{1-4}$ Defective autonomic control of the heart has received much less study. Our aim was to discover whether cardiac efferent nerves are involved in diabetic neuropathy and see how far such abnormalities might account for defective cardiovascular reflexes.

\section{Methods}

Thirteen patients who showed severe diabetic complications, including features of autonomic neuropathy, were studied (see table). None had ever been in cardiac failure and only one patient's electrocardiogram showed minor ischaemic changes. The patients lay supine for at least half an hour before the investigations. Standard electrocardio-

\section{King's College Hospital, London SE5}

R. H. LLOYD-MOSTYN, M.R.C.P., Research Fellow, Cardiac Department

(Now Senior Registrar, Queen Elizabeth Hospital, Birmingham B15 2TH)

P. J. WATKINS, M.D., M.R.C.P., Consultant Physician, Diabetic Department grams were recorded, and lead II strips were taken for measurement of heart rate. In most patients instantaneous heart rate was also recorded on tape and a tracing showing beat-to-beat variation obtained with a Hewlett-Packard heart rate monitor 8020A. Continuous intra-arterial blood pressure recordings were made in nine patients. In the remaining fourr, blood pressure was recorded with a sphygmomanometer. Cannulation of a radial artery at the wrist was performed with a Grandjean catheter introduced by a microSeldinger technique. A direct write-out of the pressure trace was obtained on a Mingograph recorder with an Elema-Schönander pressure transducer.

The following tests were used to assess the effects of the sympathetic and parasympathetic nerves in the control of heart rate.

Mental Calculation.-Subtraction tasks were rapidly performed aloud under harassment.

Tilting.-Patients were tilted to vertical for three minutes.

Valsalva Manoeuvre.-Patients blew into a modified mercury sphygmomanometer. A pressure of $40 \mathrm{~mm} \mathrm{Hg}$ was reached as soon as possible and maintained for 15 seconds. Pressure was then released abruptly and recordings were continued for at least another 20 seconds.

Phenylephrine. - Transient hypertension was induced by the intravenous Phenylephrine.- Transient hypertension was induced by the intravenous
njection of phenylephrine to test baroreceptor reflexes. A rise in systolic injection of phenylephrine to test baroreceptor reflexes. A rise in systolic
pressure of $15 \mathrm{~mm} \mathrm{Hg}$ was achieved with $50 \mathrm{\mu g}$ in all but four patients, who

Carotid Sinus Pressure. - Firm pressure was applied for 10 seconds to each carotid sinus in turn.

Amyl Nitrite.-Transient hypotension was induced by inhaling 1 ampoule of amyl nitrite, the systolic pressure falling by at least $20 \mathrm{~mm} \mathrm{Hg}$ in all patients.

After each of these tests the pulse rate and blood pressure were allowed to return as near to control levels as possible before the next test was carried out.

Propranolol.-A $10 \mathrm{mg}$ dose of propranolol was given slowly intravenously to block sympathetic stimulation of the heart.

Atropine.-Atropine $1.8 \mathrm{mg}$ was given intravenously about 30 minutes after propranolol to block vagal stimulation of the heart.

Lobeline.-On the same or a different day eight patients were given $6 \mathrm{mg}$ lobeline by rapid intravenous injection to test chemoreceptor reflex pathways.

\section{Results}

Basal Heart Rate.-In three patients the resting heart rate was over $95 / \mathrm{min}$, and in six it was 85 or more per min (fig. 1 ).

Beat-to-beat variation (sinus arrhythmia) of the heart rate on deep breathing was normal in only one patient, all the others showing variations of 7 or less per min, mostly 3 or less per min. The normal beat-to-beat variation in adults under 50 years of age is always greater than $10 / \mathrm{min}^{5}$ 
Clinical Data on Patients Studied

\begin{tabular}{|c|c|c|c|c|c|c|c|c|c|c|}
\hline $\begin{array}{l}\text { Case } \\
\text { No. }\end{array}$ & Sex & $\begin{array}{c}\text { Age } \\
\text { (Years) }\end{array}$ & $\begin{array}{l}\text { Duration of } \\
\text { Diabetes } \\
\text { (Years) }\end{array}$ & $\begin{array}{l}\text { Peripheral } \\
\text { Neuropathy }\end{array}$ & $\begin{array}{l}\text { Diabetic } \\
\text { Diarrhoea }\end{array}$ & Impotence & $\begin{array}{l}\text { Gustatory } \\
\text { Sweating }\end{array}$ & $\begin{array}{l}\text { Postural Fall } \\
\text { in B.P. } \\
(\mathrm{mm} \mathrm{Hg})\end{array}$ & Retinopathy & Proteinuria \\
\hline $\begin{array}{r}1 \\
2 \\
3 \\
4 \\
5 \\
6 \\
7 \\
8 \\
9 \\
10 \\
11 \\
12 \\
13\end{array}$ & $\begin{array}{l}\text { F. } \\
\text { M. } \\
\text { M. } \\
\text { M. } \\
\text { M. } \\
\text { F. } \\
\text { F. } \\
\text { F. } \\
\text { F. } \\
\text { M. } \\
\text { M. } \\
\text { F. } \\
\text { M. }\end{array}$ & $\begin{array}{l}27 \\
25 \\
46 \\
42 \\
47 \\
39 \\
23 \\
37 \\
34 \\
42 \\
47 \\
44 \\
37\end{array}$ & $\begin{array}{l}15 \\
12 \\
12 \\
24 \\
28 \\
31 \\
18 \\
33 \\
13 \\
30 \\
23 \\
28 \\
21\end{array}$ & $\begin{array}{l}\text { Mild } \\
\text { Severe } \\
\text { Severe } \\
\text { Severe } \\
\text { Severe } \\
\text { Mild } \\
\text { Severe } \\
\text { Severe } \\
\text { Severe } \\
\text { Severe } \\
\text { Severe } \\
\text { Moderate } \\
\text { Mild }\end{array}$ & $\begin{array}{l}+ \\
+ \\
+ \\
+ \\
+ \\
+ \\
+ \\
+ \\
+ \\
+ \\
+ \\
+\end{array}$ & $\begin{array}{c}- \\
\text { N.K. } \\
+ \\
+ \\
\pm \\
= \\
= \\
\overline{+} \\
+ \\
\pm \\
\text { N.K. }\end{array}$ & $\begin{array}{l}- \\
\pm \\
- \\
+ \\
+ \\
+ \\
+ \\
\pm \\
+ \\
+ \\
+ \\
+\end{array}$ & $\begin{array}{l}40 \\
40 \\
50 \\
35 \\
30 \\
20 \\
10 \\
20 \\
20 \\
40 \\
25 \\
40 \\
20\end{array}$ & $\begin{array}{l}\text { N.K. } \\
\text { N.V. } \\
\text { H. } \\
\text { R.P. } \\
\text { N.V. } \\
\text { H. } \\
\text { N.V. } \\
\text { R.P. } \\
\text { H.P. } \\
\text { R.P. } \\
\text { R.P. } \\
\text { N.V. } \\
\text { R.P. }\end{array}$ & $\begin{array}{l}+ \\
\pm \\
+ \\
\pm \\
+ \\
+ \\
\pm \\
+ \\
+ \\
+ \\
\pm\end{array}$ \\
\hline
\end{tabular}

N.K. = Not known. N.V. = Neovascularization. H. $=$ Haemorrhages. R.P. = Retinitis proliferans.

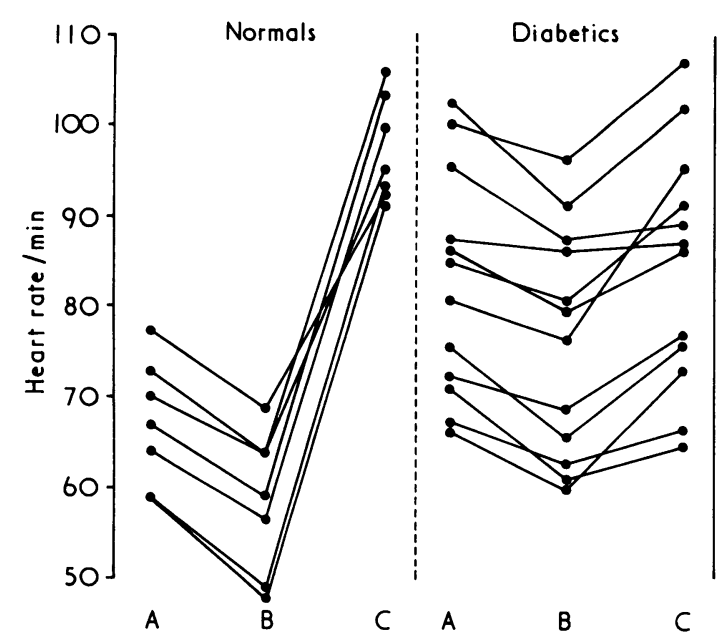

FIG. 1-Heart rates in seven normal people (from Leon et al. (ref. ${ }^{15}$ ) and personal investigations) and 12 diabetics. $\mathrm{A}=$ Aasal. $\mathrm{B}=$ After $10 \mathrm{mg}$ propranolo
After $1.8 \mathrm{mg}$ atropine intravenously.

Autonomic Blockade (fig. 1).-Propranolol $10 \mathrm{mg}$ intravenously slows the heart by at least 8 beats/min in most normal people. The response was normal in four patients but impaired in most, and in four there was a slowing of less than 5 beats/min. Normally the increase in heart rate caused by atropine is far greater than the slowing caused by propranolol. All our patients showed a small response to atropine; thus the heart rates after blockade with both drugs were similar to the resting rates. There was a wide distribution of heart rates after blockade of both sympathetic and parasympathetic nerves (intrinsic heart rate). In five patients the intrinsic heart rate was much lower than expected for their age. ${ }^{6}$ One patient (case 1) showed no significant response to either propranolol or atropine.

Phenylephrine.-Slowing of the heart was negligible in most patients despite increases in systolic pressure of at least $15 \mathrm{~mm} \mathrm{Hg}$ (fig. 2). The corresponding baroreceptor sensitivities ${ }^{7}$ of 0 to $7 \mathrm{~ms} /$ $\mathrm{mm} \mathrm{Hg}$ were all below those found in normal people of similar age. ${ }^{8}$

Mental Calculation. - With this test the increase in heart rate varied from 0 to 19 beats $/ \mathrm{min}$.

Tilting.-With tilting the increase in heart rate varied from 1 to 18 beats/min and was always prevented by propranolol (fig. 3). There was poor correlation between responses to tilt and calculation.

Amyl Nitrite.-Heart rate responses to the hypotension induced by amyl nitrite were small (fig. 2), with corresponding baroreceptor sensitivities of 0 to $2.0 \mathrm{~ms} / \mathrm{mm} \mathrm{Hg}$. Propranolol had little effect on these responses (fig. 3), in contrast to its effect on the rate increase induced by tilting.

Valsalva Manoeuvre.-In all nine patients whose intra-arterial pressure was recorded the strain phase was effective as judged by a fall in the mean pressure and the pulse pressures, and only three patients showed no tachycardia. Two patients showed a normal "overshoot" and hence a completely normal blood pressure response, and one other patient showed a slight "overshoot." The changes in heart rate associated with the Valsalva manoeuvre were abnormally small in all patients. Reflex bradycardia was absent in seven patients and small in the remainder, and even in the two patients with a normal "overshoot" almost no heart slowing resulted. Comparison with the responses after

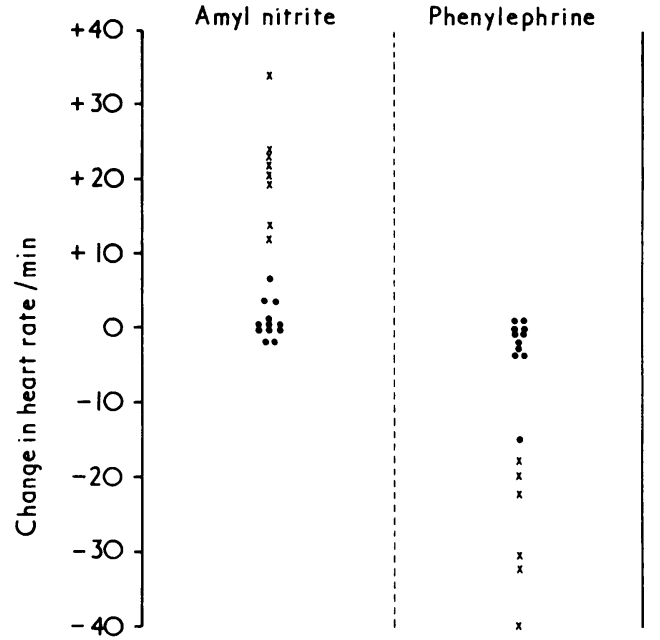

FIG. 2-Changes in heart rate due to $20 \mathrm{~mm} \mathrm{Hg}$ increase and decrease in systolic blood pressure induced by phenylephrine and amyl nitrite respectively. $=$ Diabetics. $\times=$ Normal people (taken from Leon et al. (ref. $\left.{ }^{15}\right)$ ). Figures were obtained by extra polationon basis of known linear relationship between blood pressure and pulse interval (Smyth et al. $\left(\right.$ ref. $\left.\left.^{7}\right)\right)$.

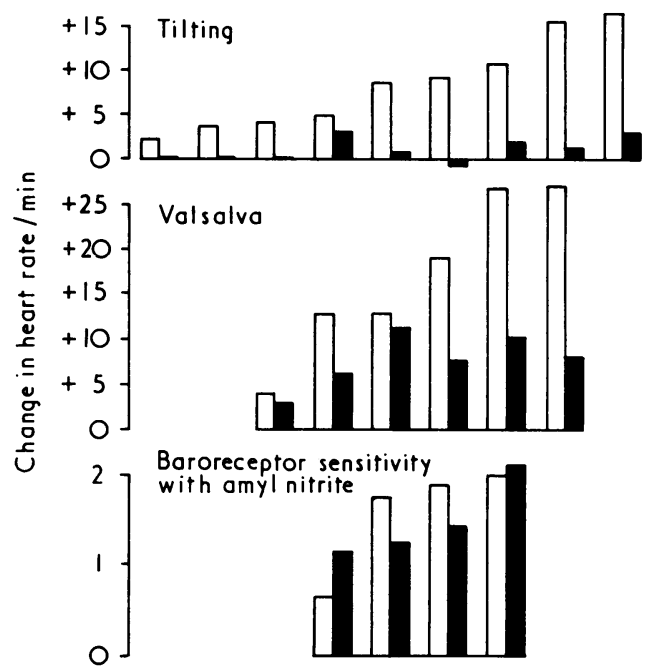

FIG. 3-Reflex changes in heart rate in individual patients associated with tilting, strain phase of Valsalva manoeuvre, and administration of amyl nitrite (expressed as baroreceptor sensitivity). For each patient white column shows change without propranolol and shaded column shows change after administration of propranolol.

propranolol (fig. 3) indicates that increased sympathetic activity played a larger part than parasympathetic withdrawal in the three patients who showed the largest rise in heart rate during theValsalva manoeuvre. 
Carotid Sinus Pressure.-In most patients responses were small, as would be expected from the poor response to phenylephrine. Nevertheless, in two patients the heart rate slowed by 26 beats/min despite small responses to phenylephrine.

Lobeline.-Seven of the eight patients given lobeline showed the normal response of coughing and hyperventilation.

\section{Discussion}

Defective autonomic control of the heart was found in all these patients with diabetic neuropathy, all of whom had many diabetic complications as well as features of autonomic neuropathy. Impairment of vagal function was the most easily recognized abnormality and occurred in all the patients, and generally there was good correlation between the different tests of vagal function. Abnormalities of sympathetic function were less common and generally less severe. Vagal impairment sometimes occurred without any sympathetic involvement but not the reverse. In one case the heart appeared to be totally denervated.

We believe that the neuropathy chiefly affects the efferent cardiac nerves rather than afferent pathways. Poor heart rate responses to autonomic blockade and diminished beat-to-beat variation provide positive evidence for efferent abnormalities. Beat-to-beat variation is mediated by the vagus nerve, since it is abolished by atropine ${ }^{5}$ and, in animals, section of the vagi. ${ }^{9}$ Total unresponsiveness of the heart rate in case 1 could be due only to efferent involvement. Sharpey-Schafer and Taylor ${ }^{10}$ attributed abnormal cardiovascular responses to an afferent baroreceptor lesion, but such a lesion could not explain all our findings; multiple afferent pathways would have to be involved, and at least our own patients had normal afferent chemoreceptor responses to lobeline.

Sympathetic defects were also common but generally less severe and more difficult to assess. This is because the responses to tests which stimulate the sympathetic nerve are often small compared with those acting through the vagus, and sympathetic blocking drugs such as propranolol normally have a much smaller effect on the heart rate than parasympathetic blockers such as atropine (fig. 1). In some patients the heart rate slowing due to propranolol was normal. Responses to tilting and calculation were, however, often small or absent. In two patients good sympathetic function co-existed with severe vagal defect.

The patient with complete cardiac denervation showed no significant response of the heart rate to any test of autonomic function, though there was a small increase after exercise. This constancy of heart rate is similar to that of a transplanted heart, which is, of course, a denervated organ. ${ }^{11}$ The patient was a 27 -year-old woman with longstanding diabetes. She was almost disabled by postural hypotension and suffered from other autonomic defects including diarrhoea and urinary retention. Peripheral neuropathy was present but mild.

There are numerous clinical consequences of a denervated heart. The persistent tachycardia observed in some diabetics is a result of vagal impairment. ${ }^{512-14}$ The fixed heart rate which is occasionally observed may have more serious effects. Inability to increase cardiac output would contribute to the hypotension induced by standing or exercise and impair the ability to undertake strenuous exercise. Lack of response to $\beta$-blockade could result in a therapeutic failure of drugs to slow tachycardia or relieve angina. On the other hand, denervation hypersensitivity to catecholamines is a possible hazard and might account for the five cardiac arrests witnessed in three of our patients with extensive autonomic neuropathy.

We conclude that defects of both sympathetic and parasympathetic nerves to the heart may occur in diabetics and are common in highly selected patients with other evidence of autonomic neuropathy. Autonomic neuropathy may be readily detected by tests which entail measurement of heart rate, of which beat-to-beat variation on deep breathing is probably the best. Occasionally the heart may be totally isolated from autonomic control. Denervation of the heart may predispose to serious dysrhythmias.

We thank Dr. S. Oram and Dr. D. A. Pyke for their advice and encouragement, and Mrs. Rowena Oakley and staff of the cardiac department for technical help. We are grateful to Dr. Trevor Shelley and Mr. Tony Murrill, who developed the technique for taperecording "beat-to-beat" variation. R. H. Lloyd-Mostyn was supported by a grant from Boehringer Ingelheim, and Mrs. Rowena Oakley by a grant from the British Diabetic Association.

\section{References}

1 Barany, F. R., and Cooper, E. R., Clinical Science, 1956, 15, 533.

2 Moorhouse, J. A., Carter, S. A., and Doupe, J., British Medical fournal, $1966,1,883$

3 Christensen, N. J., Acta Medica Scandinavica, 1968, 183, 449.

4 Christensen, N. J., Acta Medica Scandinavica, 1973, Suppl. No. 541.

5 Wheeler, T., and Watkins, P. J., British Medical fournal, 1973, 4, 584.

6 Jose, A. D., and Collison, D., Cardiovascular Research, 1970, 4, 160.

7 Smyth, H. S., Sleight, P., and Pickering, G. W., Circulation Research, $1969,24,109$.

${ }^{8}$ Pickering, T. G., et al., Circulation Research, 1972, 30, 177.

9 Samaan, A., Fournal of Physiology, 1935, 83, 332.

10 Sharpey-Schafer, E. P., and Taylor, P. J., Lancet, 1960, 1, 559.

11 Griepp, R. B., et al., Surgery, 1971, 70, 88 .

11 Griepp, R. B., et al., Surgery, $1971,70,88$. und für klinische Medizin, 1892, 127, 1 .

13 Martin, M. M., Lancet, 1953, 1, 560.

14 Keen, H., Postgraduate Medical fournal, 1959, 35, 272. 15 Leon, D. F., Shaver, J. A., and Leonard, J. J., American Heart Fournal,
1970, 80, 729 . 